\title{
Association of quality of life of urban elderly with socio-demographic factors
}

\section{Debalina Datta, Pratyay Pratim Datta ${ }^{1}$, Kunal Kanti Majumdar ${ }^{2}$}

Public Health, Sai Nath University, Ranchi, 'World Health Organization, Godda, Jharkhand,

${ }^{2}$ Department of Community

Medicine, KPC Medical College and Hospital, Kolkata, West

Bengal, India

Address for the Correspondence:

Dr. Pratyay Pratim Datta, World Health Organization, SMO-WHO Office, Sadar Hospital

Campus, Godda - 814133 Jharkhand, India.

E-mail: pratyaypratimdatta@ gmail.com

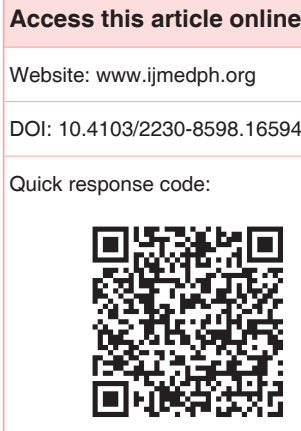

Introduction: Quality of life (QOL) of elderly often deteriorates due to many factors. This study was planned to find out the different domains of QOL of elderly people affected by socio-demographic factors. Materials and Methods: This was a community-based cross-sectional study conducted in Kolkata and Sonarpur area of West Bengal, India from January to December, 2013. The qQOL questionnaire developed by World Health Organization was used (BREF). The scores of QOL were assessed in the light of different socio-demographic characteristics. Results and Analysis: The QOL was significantly lower among people having more age, female, illiterate, financially fully dependent and those having lower socio-economic status. Conclusion: QOL is an important determinant of the living status of elderly and socio-demographic factors determine the QOL in this age group.

Key words: Elderly, socio-demographic factors, quality of life

\section{INTRODUCTION}

Quality of life (QOL) is an individual's understanding of his/her life situation with respect to his/her values and cultural context as well as in relation to his/her goals, expectations and concerns. QOL has many dimensions such as material well-being, close relationships, health, emotional well-being, and productivity. QOL differs from individual to individual and is dependent on different factors. As the demographic pattern has changed with more elderly people, the overall QOL of a nation has also changed. ${ }^{[1]}$ Loneliness, social disconnection, poor physical and mental health status contribute to poor QOL of elderly. This study has been planned to find out the different domains of QOL of elderly people affected by socio-demographic factors.

\section{MATERIALS AND METHODS}

\section{Study area}

This study was conducted in two urban communities of the southern part of West Bengal, India. One of the two communities was selected in the metropolitan area (Kolkata) and other in the nonmetropolitan area (Sonarpur).

\section{Study population}

The study was conducted among people aged 60 years and above (geriatric people). Date was collected from 472 geriatric people.

This is an open access article distributed under the terms of the Creative Commons AttributionNonCommercial-ShareAlike 3.0 License, which allows others to remix, tweak, and build upon the work non-commercially, as long as the author is credited and the new creations are licensed under the identical terms.

For reprints contact: reprints@medknow.com

How to cite this article: Datta D, Datta PP, Majumdar KK. Association of quality of life of urban elderly with socio-demographic factors. Int J Med Public Health 2015;5:274-8. 


\section{Study period}

The study was conducted from January to December, 2013.

\section{Study design}

It was a community-based cross-sectional study.

\section{Study tools}

- One predesigned, pretested, semi-structured questionnaire was used to collect data regarding the socio-demographic parameters.

- $\quad$ QOL was assessed using QOL BREF questionnaire developed by World Health Organization (WHO). ${ }^{[1]}$ Permission to use this questionnaire was taken from WHO and they supplied Bengali version of the questionnaire. The questionnaire has four domains:

- Physical domain.

- Psychological domain.

- Social interaction domain.

- Environmental domain.

- In addition, one question each for overall QOL and overall health status.

WHOQOL-BREF is a subset of 26 items taken from WHOQOL-100. Each domain raw score is converted to a $0-100$ scale using the formula of transformed scale.

Transformed score $=([$ actual raw score - lowest possible raw score $] /$ possible raw score range) $\times 100$.

This transformation converts the lowest and highest possible scores to 0 and 100 respectively. The scores between these values represent the percentage of the total possible raw score achieved.

\section{Sample design}

The sampling was done using a stratified random sampling method. One district having metropolitan city and one other district were selected. Kolkata is the main metropolitan city, and so it was selected. Out of rest 19 districts in West Bengal, one was selected using a simple random sampling technique. The selected district was South 24 Parganas. In Kolkata district, there are 15 boroughs out of which borough VIII was selected using a simple random sampling technique. Two wards out of 12 wards in borough VIII were selected using a simple random sampling technique. In South 24 Parganas, Sonarpur municipality was chosen using simple random sampling technique and in this area two wards were selected using simple random sampling. In the selected wards, all elderly people were encouraged to take part in the present study. The study was done among those elderly people who gave informed consent to take part in the study.

The study was conducted after clearance from Institutional Ethics Committee.

\section{Study technique}

Data were collected by interviewing study subjects by the house to house visits.

\section{Statistical analysis}

After collection of data, it was double entered in Microsoft Excel sheet for verification. The clean data set was copied into SPSS IBM sheet (version 16.0) for analysis. For demographic factors having binary outcome independent sample $t$-test was used to find out their relationship with QOL score. For socio-demographic factors having more than two categorical outcomes, ANOVA was used and for socio-demographic factors having the continuous outcome correlation test was used. $P<0.05$ was considered to be statistically significant.

\section{RESULT}

This study highlighted the association of socio-demographic factors with QOL score of the study population. Table 1 shows that the majority (40.3\%) of the elderly were in the age group of 60-64 years. $17.6 \%$ were in the age group of $65-69$ years, $16.3 \%$ were in the age group of $70-74$ years, $14.6 \%$ of the elderly were aged 80 years and above and only $11.2 \%$ were in the age group of $75-79$ years of age. The percentage of female elderly $(50.6 \%)$ was slightly more than male $(49.4 \%)$. The majority of the study participants were Hindu

\begin{tabular}{lc}
\multicolumn{2}{l}{ Table 1: Socio-demographic characteristics of the } \\
study population \\
\hline Parameters \\
\hline Age $(\%)$ \\
$60-64$ years & $190(40.3)$ \\
$65-69$ years & $83(17.6)$ \\
$70-74$ years & $77(16.3)$ \\
$75-79$ years & $53(11.2)$ \\
80 years and above & $69(14.6)$ \\
Sex & \\
Male & $233(49.4)$ \\
Female & $239(50.6)$ \\
Religion & \\
Hindu & $392(83.1)$ \\
Muslim & $80(16.9)$ \\
Educational status & \\
Illiterate & $210(44.5)$ \\
Up to primary & $187(39.6)$ \\
Up to secondary & $16(3.4)$ \\
Up to higher secondary & $29(6.1)$ \\
Graduate or above & $30(6.4)$ \\
Independent & \\
Partially dependent & $195(41.3)$ \\
Fully dependent & $22(4.7)$ \\
\hline & $255(54.0)$ \\
\hline
\end{tabular}


(83.1\%) Only 16.9\% were from the Muslim community. Most of the study respondents were illiterate (44.5\%). 39.6\% had primary level education, $3.4 \%$ had secondary level education, $6.1 \%$ had higher secondary level education and $6.4 \%$ were graduate or above. The majority of the respondents were financially fully dependent on others (54\%), $41.3 \%$ were independent and $4.7 \%$ were partially dependent. Table 2 highlights that mean of transformed scores of QOL is maximum in the environmental health domain (48.36) and minimum in the social relationship domain (39.62). Table 3 shows that with an increase in age the scores of QOL decrease significantly in all domains $(P<0.001$ in the physical, psychological, and social interaction domain and $P=0.002$ in the environmental domain).

Figure 1 highlights that QOL scores were significantly more in males than females $(P<0.001)$ in all domains. Figure 2 shows that there was no significant difference in QOL between elderly persons of different religions $(P>0.05)$ in any domain. Table 4 highlights that QOL score improved significantly with an increase in per capita income ( $P<0.05$ in all domains except social interaction domain). Table 5 shows that scores in all domains of QOL of people who were illiterate or had primary level education were significantly lower than people who had an educational level at the secondary level and above. In all domains excluding the physical health domain the scores of the illiterate population were also significantly lower than people having a primary level education. Table 6 indicates that in physical health and psychological health domain the study population who were independent or partially dependent had better QOL scores than those who were fully dependent. In the rest two domains, that is, the social relationship and environmental domain the independent study population had significantly better QOL scores than those who were fully dependent.

\section{DISCUSSION}

The present study has highlighted the association of sociodemographic parameters with QOL scores of the study population.

The present study has found out that QOL deteriorates significantly with an increase in age. A study was done by Joshi et al., it was seen that health-related QOL score was associated with age. ${ }^{[1]}$ In a study

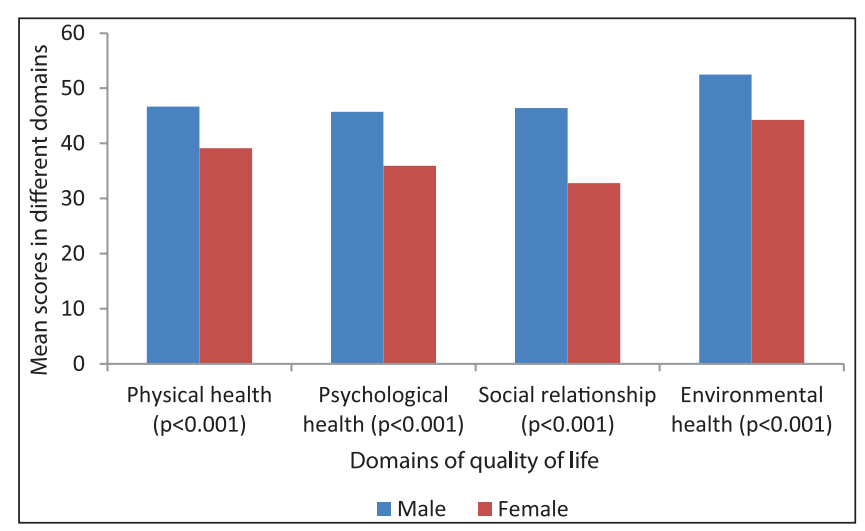

Figure 1: Relationship of sex with quality of life score of the study population by Lakshmi Devi et al., it was found that QOL significantly decreased with increase in age. ${ }^{[2]}$ This finding was corroborated with a study conducted by Kumar et al. on QOL of elderly in urban Puduchery in 2013. ${ }^{[3]}$ They found that older age was associated with poor QOL. In another study conducted by Lokare et al., they found that QOL was significantly better among young people. ${ }^{[4]}$ This finding is corroborated with the finding of a study done by Lahariya $e t$ al. ${ }^{[5,6]}$

As the age advances, the health related problems become more common to a person. Gradually and gradually the power to work decreases and people are more confined to his/her own house. In this scenario loneliness is a very common problem. As age increases, the chance of losing spouse becomes more. In that scenario, loneliness increases to a much greater extent. So, overall the physical and psychological QOL becomes poorer with the advancement of age. Beside this, the social interaction decreases with increased age. So, the social relationship domain of QOL becomes worse.

\begin{tabular}{lcc} 
Table 2: Transformed scores of QOL \\
\hline Domains & Mean score & SD \\
\hline Physical health & 42.26 & 15.64 \\
Psychological health & 40.84 & 15.64 \\
Social relationship & 39.62 & 16.39 \\
Environmental & 48.36 & 13.18 \\
\hline
\end{tabular}

$\mathrm{SD}=$ Standard deviation, $\mathrm{QOL}=$ Quality of life

Table 3: Relationship of age with QOL of the study
population
\begin{tabular}{llcc} 
Area & Domain & Correlation coefficient & $\boldsymbol{P}$ \\
\hline Total & Physical & -0.335 & $<0.001$ \\
$(n=472)$ & Psychological & -0.201 & $<0.001$ \\
& Social & -0.215 & $<0.001$ \\
& Environmental & -0.142 & 0.002 \\
\hline
\end{tabular}

$\mathrm{QOL}=$ Quality of life

Table 4: Relationship of per capita income with
QOL score
\begin{tabular}{llcc} 
Area & Domain & Correlation coefficient & $\boldsymbol{P}$ \\
\hline Total & Physical & 0.101 & 0.029 \\
$(n=472)$ & Psychological & 0.192 & $<0.001$ \\
& Social & 0.081 & 0.080 \\
& Environmental & 0.244 & $<0.001$ \\
\hline
\end{tabular}

$\mathrm{QOL}=$ Quality of life

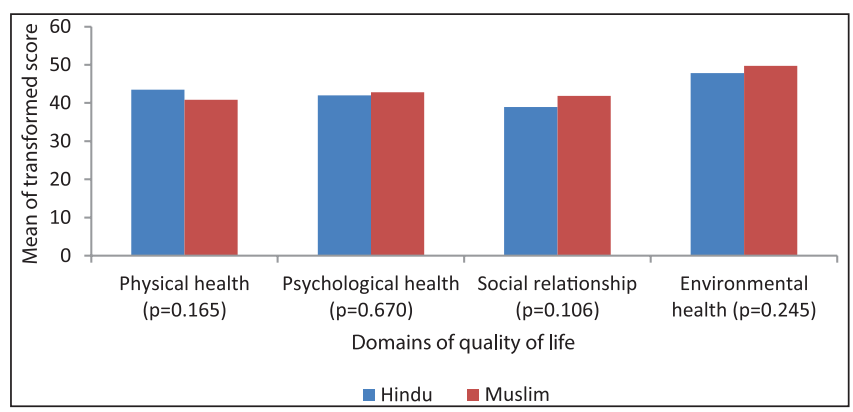

Figure 2: Scores of different domains of quality of life according to religion of the study population 


\begin{tabular}{|c|c|c|c|c|c|}
\hline \multirow[t]{2}{*}{ Domain } & \multirow[t]{2}{*}{ Comparing groups } & \multirow{2}{*}{$\begin{array}{c}\text { Mean } \\
\text { difference }\end{array}$} & \multirow[t]{2}{*}{$P$} & \multicolumn{2}{|c|}{$95 \% \mathrm{Cl}$} \\
\hline & & & & Lower & Upper \\
\hline \multirow[t]{5}{*}{ Physical } & Illiterate & & & & \\
\hline & Primary & -2.754 & 0.172 & -6.357 & 0.849 \\
\hline & Secondary and above & -10.670 & $<0.001$ & -15.490 & -5.850 \\
\hline & Primary & & & & \\
\hline & Secondary and above & -7.916 & $<0.001$ & -12.814 & -3.018 \\
\hline \multirow[t]{5}{*}{ Psychological } & Illiterate & & & & \\
\hline & Primary & -6.174 & $<0.001$ & -9.682 & -2.666 \\
\hline & Secondary and above & -12.349 & $<0.001$ & -17.042 & -7.656 \\
\hline & Primary & & & & \\
\hline & Secondary and above & -6.175 & 0.007 & -10.943 & -1.407 \\
\hline \multirow[t]{5}{*}{ Social } & Illiterate & & & & \\
\hline & Primary & -6.642 & $<0.001$ & -10.344 & -2.940 \\
\hline & Secondary and above & -13.754 & $<0.001$ & -18.707 & -8.801 \\
\hline & Primary & & & & \\
\hline & Secondary and above & -7.112 & 0.003 & -12.144 & -2.080 \\
\hline \multirow[t]{5}{*}{ Environmental } & Illiterate & & & & \\
\hline & Primary & -6.804 & $<0.001$ & -9.696 & -3.932 \\
\hline & Secondary and above & -14.470 & $<0.001$ & -18.313 & -10.627 \\
\hline & Primary & & & & \\
\hline & Secondary and above & -7.662 & $<0.001$ & -11.571 & -3.762 \\
\hline
\end{tabular}

\begin{tabular}{|c|c|c|c|c|c|}
\hline \multirow[t]{2}{*}{ Domain } & \multirow[t]{2}{*}{ Groups } & \multirow{2}{*}{$\begin{array}{c}\text { Mean } \\
\text { difference }\end{array}$} & \multirow[t]{2}{*}{$P$} & \multicolumn{2}{|c|}{$95 \% \mathrm{Cl}$} \\
\hline & & & & Lower & Upper \\
\hline \multirow[t]{5}{*}{ Physical } & Independent & & & & \\
\hline & Partially dependent & 0.827 & 0.967 & -7.081 & 8.734 \\
\hline & Fully dependent & 9.476 & $<0.001$ & 6.132 & 12.821 \\
\hline & Partially dependent & & & & \\
\hline & Fully dependent & 8.650 & 0.026 & 0.837 & 16.462 \\
\hline \multirow[t]{3}{*}{ Psychological } & Independent & & & & \\
\hline & Partially dependent & -0.051 & 1.000 & -7.962 & 7.859 \\
\hline & Fully dependent & 8.106 & $<0.001$ & 4.760 & 11.452 \\
\hline \multirow[t]{5}{*}{ Social relationship } & Independent & & & & \\
\hline & Partially dependent & 5.715 & 0.220 & -2.356 & 13.786 \\
\hline & Fully dependent & 12.474 & $<0.001$ & 9.060 & 15.888 \\
\hline & Partially dependent & & & & \\
\hline & Fully dependent & 6.759 & 0.115 & -1.216 & 14.733 \\
\hline \multirow[t]{5}{*}{ Environmental } & Independent & & & & \\
\hline & Partially dependent & 0.855 & 0.952 & -5.872 & 7.582 \\
\hline & Fully dependent & 7.178 & $<0.001$ & 4.332 & 10.023 \\
\hline & Partially dependent & & & & \\
\hline & Fully dependent & 6.322 & 0.066 & -0.324 & 12.969 \\
\hline
\end{tabular}

In a study conducted by Joshi et al., the association of health-related QOL with sex was highlighted. ${ }^{[1]}$ A study conducted by Qadri et al., it was found that the QOL was significantly better in the male sex. ${ }^{[7]}$ In another study by Lokare et al., they have found that QOL was significantly better among male elderly. ${ }^{[4]}$ This finding is matched with the finding of a study done by Lahariya et al. ${ }^{[5]}$ Male participants scored significantly higher in all domains in the present study than females. Kumar et al. have also found that gender played an important and significant role in determining QOL of elderly. ${ }^{[8]}$ Like these studies another study conducted by Ibrahim et al. also found that men scored significantly better in QOL in Iraq. ${ }^{[9]}$ According to study by Muhwezi et al. in Uganda, they found that females scored significant poor QOL in the physical health domain in WHOQOL-BREF questionnaire. ${ }^{[10]}$

The present study has showed that with an increase in per capita monthly income the QOL score improve significantly. The increase in per capita income indicates better socio-economic status. A study conducted by Nilsson et al. in Bangladesh also showed that poor 
economic status was a significant determinant of poor QOL among the elderly. ${ }^{[11]}$ In a study conducted by Kumar et al., they have found that socio-economic status played an important and significant role in determining the QOL of elderly. ${ }^{[8]}$ The Brazilian version of WHOQOL-BREF was used to study the QOL of elderly in Brazil by Alexandre Tda et al. They also found that income had an impact on the QOL. ${ }^{[12]}$ Niedzwiedz CL et al. found that individuals having poor socioeconomic status had lower QOL score. ${ }^{[13]}$

Elderly people live with many physical as well as mental problems, and social detachment deteriorates the condition. QOL of elderly people is closely associated with different socio-demographic factors. The triple evils of ill-health, loneliness, and social disconnection deteriorate the QOL of elderly. The modern philosophy is that old must continue to take their responsibilities and in the enjoyment of the privileges like others. Social interaction can directly or indirectly assist the aged to fight the triple evils of ill health, loneliness, and social disconnection.

\section{Financial support and sponsorship}

Nil.

\section{Conflicts of interest}

There are no conflicts of interest.

\section{REFERENCES}

1. Joshi K, Avasthi A, Kumar R. Health-related Quality of Life (HRQOL) among elderly in Northern India. Health Popul Perspect Issues
2003;26:14M53.

2. Lakshmi Devi S, Roopa KS. Quality of life of elderly men and women in institutional and noninstitutional settings in urban Bangalore District. Res J Family Community Consum Sci 2013;1:7-13.

3. Kumar SG, Majumdar A, Pavithra G. Quality of Life (QOL) and its associated factors using WHOQOL-BREF among elderly in urban Puducherry, India. J Clin Diagn Res 2014;8:54-7.

4. Lokare L, Nekar MS, Mahesh V. Quality of life and restricted activity days among the old aged. Int J Biol Med Res 2011;2:1162-4.

5. Lahariya C, Khandekar J, Pradhan SK. A community based study of health related quality of life of the elderly in urban India. J Indian Med Assoc 2012;110:548-50, 559.

6. Sharma A, Hindman HB. Aging: A predisposition to dry eyes. J Ophthalmol 2014;2014:781683.

7. Qadri SS, Ahluwalia S, Ganai AM, Balisps, Wani FA, Bashir H. An epidemiological study on quality of life among rural elderly population of nothern India. Int J Med Sci Public Health 2013;2:514-22.

8. Kumar KV, Sivan YS, Reghu JR, Das R, Kutty VR. Health of the elderly in a community in transition: A survey in Thiruvananthapuram City, Kerala, India. Health Policy Plan 1994;9:331-6.

9. Ibrahim TM, Namir GA, Tariq SA, Nazar PS. Quality of life and morbidity pattern of Geriatric population in Erbil City. Middle East J Age Ageing 2010;7:233-250. Available from: http://www.me-jaa.com/mej'aaFeb2010/ Quality.htm Last accessed on Oct, 2013.

10. Muhwezi WW, Okello ES, Turiho AK. Gender-based profiling of Quality of Life (QOL) of primary health care (PHC) attendees in central Uganda: A cross sectional analysis. Afr Health Sci 2010; 10:374-85.

11. Nilsson J, Rana AK, Kabir ZN. Social capital and quality of life in old age: Results from a cross-sectional study in rural Bangladesh. J Aging Health 2006;18:419-34.

12. Alexandre Tda S, Cordeiro RC, Ramos LR. Factors associated to quality of life in active elderly. Rev Saude Publica 2009;43:613-21.

13. Niedzwiedz CL, Katikireddi SV, Pell JP, Mitchell R. Socioeconomic inequalities in the quality of life of older Europeans in different welfare regimes. Eur J Public Health 2014;24:364-70. 